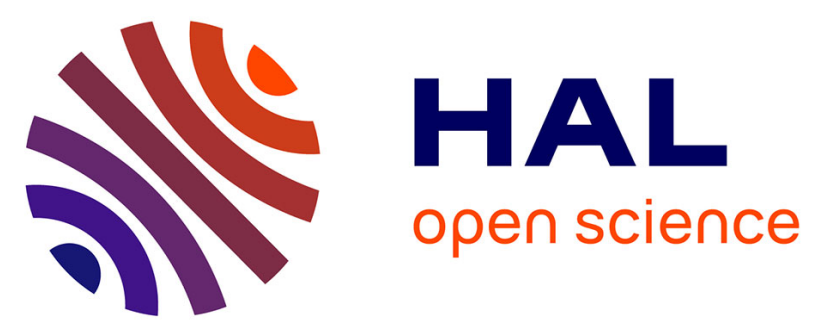

\title{
3D nodal method architectures for transient thermal modelling of an induction motor taking into account the variation of stator and rotor pole numbers
}

Shinara Utegenova, Raynal Glises, Philippe Désévaux, Damien Mariotto, Bertrand Truffart

\section{To cite this version:}

Shinara Utegenova, Raynal Glises, Philippe Désévaux, Damien Mariotto, Bertrand Truffart. 3D nodal method architectures for transient thermal modelling of an induction motor taking into account the variation of stator and rotor pole numbers. International Conference on Power Electronics, Machines and Drives, Apr 2016, Glasgow, United Kingdom. hal-02130743

\section{HAL Id: hal-02130743 \\ https://hal.science/hal-02130743}

Submitted on 16 May 2019

HAL is a multi-disciplinary open access archive for the deposit and dissemination of scientific research documents, whether they are published or not. The documents may come from teaching and research institutions in France or abroad, or from public or private research centers.
L'archive ouverte pluridisciplinaire HAL, est destinée au dépôt et à la diffusion de documents scientifiques de niveau recherche, publiés ou non, émanant des établissements d'enseignement et de recherche français ou étrangers, des laboratoires publics ou privés. 


\title{
3D nodal method architectures for transient thermal modelling of an induction motor taking into account the variation of stator and rotor pole numbers
}

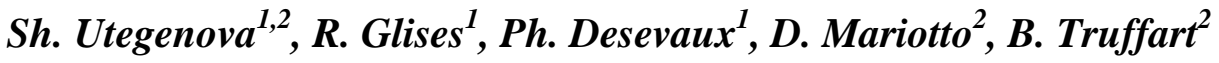 \\ ${ }^{I}$ Femto-ST laboratory, Energy Department (UMR CNRS 6174), \\ University of Bourgogne Franche-Comte (UBFC), Belfort, France, \\ ${ }^{2}$ Airbus Helicopters, Marignane, France
}

Keywords: Electrical machine, thermal nodal method, pole number variation, 3D thermal design

\begin{abstract}
This paper is dealing with the transient thermal modelling of high-speed asynchronous machines for helicopter using nodal method. The main goal of this work is to choose a nodal network structure for a generalized numerical tool aiming to precisely predict the thermal behaviour of high speed asynchronous machines at steady state as well as in transient mode, taking into account geometry variations of the machine, particularly stator and rotor pole numbers variation.

In this paper the studied machine is a $29 \mathrm{~kW}, 12000 \mathrm{rpm}$ high speed asynchronous motor including water cooling jacket.
\end{abstract}

\section{Introduction}

Nowadays, the electric propulsion system enters intensely in the aerospace world [1]. The machine technologies are compared in the context of their performances, dimensions and ability to satisfy the specific safety requirements. Once dimension and performance requirements are defined, the thermal design permits to identify the correspondence of the machine to the safety specifications.

In this article, thermal modelling using nodal method for high-speed asynchronous machines for helicopter use is discussed. This well-grounded method consists in 3D discretization of the induction motor into isothermal volumes linked together with thermal conductivities that represent different types of internal thermal transfers [2]. These thermal conductivities represent the conduction, convection and radiation phenomenon, as well as the mass flow in the cooling ducts. In this modelling of an asynchronous motor, the radiation phenomenon is neglected because of the relatively low level of reached temperature of such machines, particularly on their external surfaces.

While the variation of the values of the main dimensions does not influence on the calculation architecture, stator and rotor tooth number variation requires a modification of the whole nodal network.

This work is aimed to compare different approaches of network architecture strategy, permitting to keep the same nodal network independently of the pole number variation. As a result, a symmetrical simplification stays valid, permitting to keep the minimal number of nodes without reducing the precision of the model with respect to the poles symmetries for rotor and stator.

\section{Nodal network architectures}

\subsection{Context}

The number of stator and rotor slots varies from one machine configuration to another, and usually it is not the same for rotor and stator as shown in Figure 1.

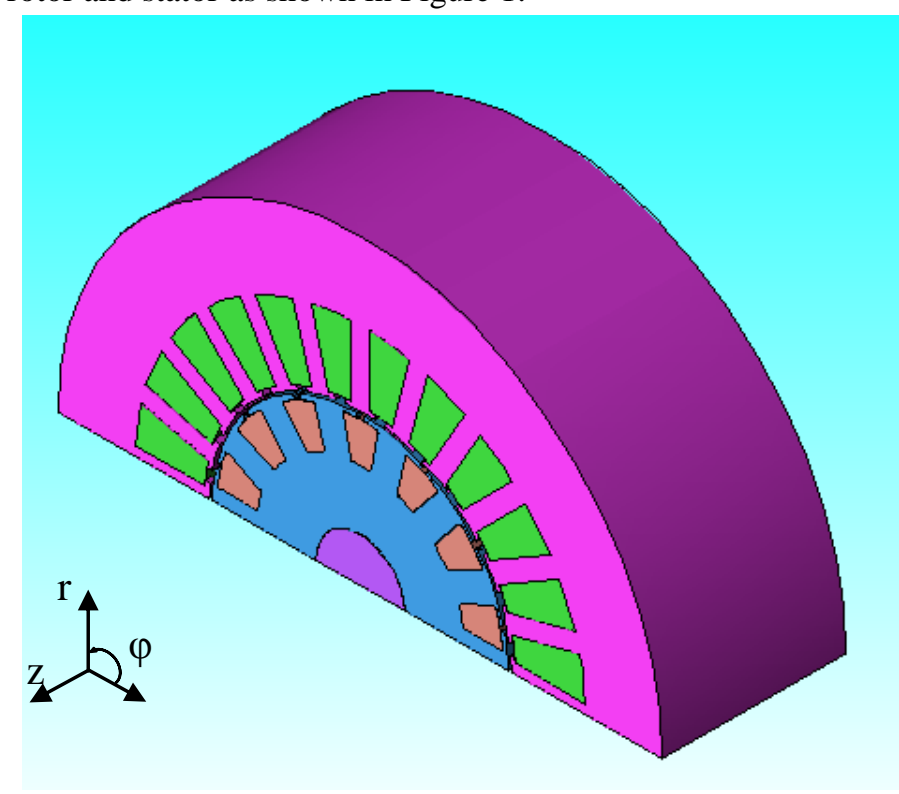

Figure 1: Machine halved geometry

Figure 2 shows that there are thermals resistances in $\varphi$-axis direction of cylindrical coordinate system, which doesn't 
permit to reduce the thermal resistances network in the same way as if it was an electric circuit with parallel paths.

So with the variation of number of slots, the number of $\varphi$-axis thermal resistances varies also, modifying the whole nodal network. Taking into account all the slot numbers leads to increase considerably the number of nodes, so modelling of each machine configuration separately leads to an important time cost.
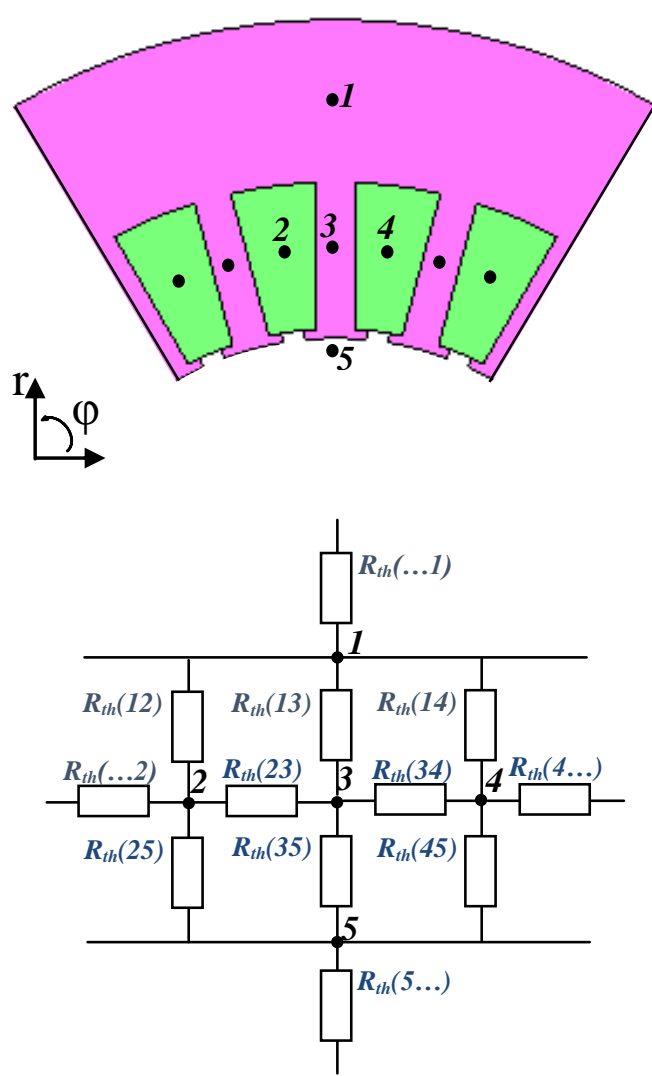

Figure 2: Thermal resistances network part

As a result, a generalized nodal network independent on slot number variation couldn't be developed without simplifications.

In this work three different nodal architecture strategies are studied. The results obtained with these architectures are compared to experimental test results from the literature in order to examine the accuracy of each one.

\subsection{First architecture}

Division of stator and rotor geometries by number of stator and rotor slots respectively may seem to be the most evident and feasible solution, because in that case the number of nodes is the same for no matter what motor geometry, and so the nodal network architecture remains constant.

However, as it could be seen in Figure 3 the pole angle of the stator is rarely the same as the pole angle of the rotor.
So the thermal flux generated in the stator does not correspond to that of the rotor, so the thermal model based on this theory is not accurate.

It seems to be interesting however to propose some simplifications in order to keep this architecture and to compare it with the other approaches.

As one of the proposed simplifications it could be suggested to introduce a coefficient depending on ratio of rotor and stator slot numbers permitting the adjustment of stator and rotor heat fluxes (along the radius) in accordance with chosen rotor or stator pole angle.

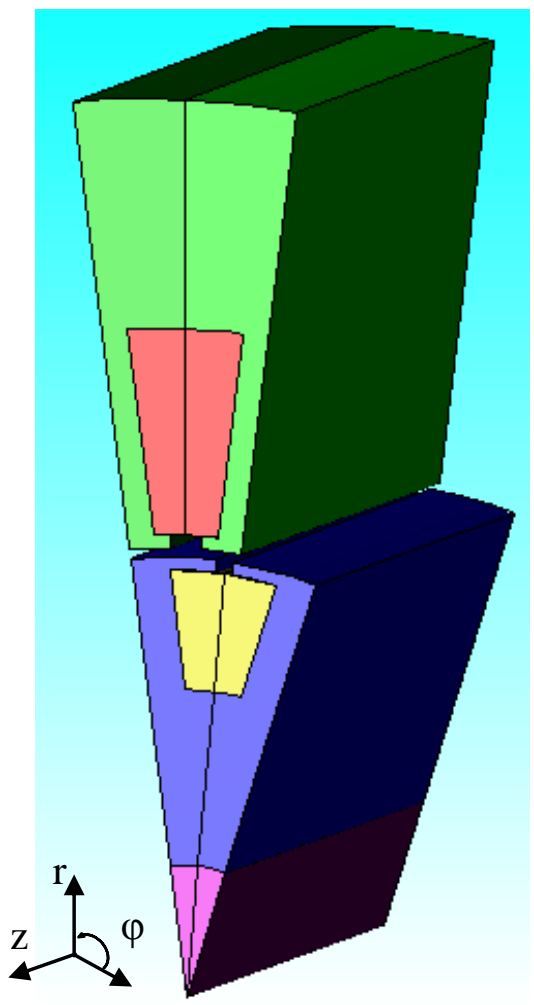

Figure 3: Stator and rotor geometry divided by number of stator and rotor slot numbers respectively

\subsection{Second architecture}

As the slots, and as a consequence electrical windings inside the slots, are thermally isolated in the radial and orthoradial directions, the $\varphi$-axis resistances between slots and teeth are high enough so that the heat exchanges in this direction could be neglected. The equivalent resistances taking into account stator and rotor slot numbers variation could be easily calculated without changing number of nodes as shown in Figure 4.

This simplification leads to introduce a coefficient permitting to adjust the contact surface among winding, tooth and yoke.

The advantage of this method is the fact that it permits to model the whole machine in such a way that thermal flux passing between stator and rotor is appropriate and the number of nodes remains constant. 


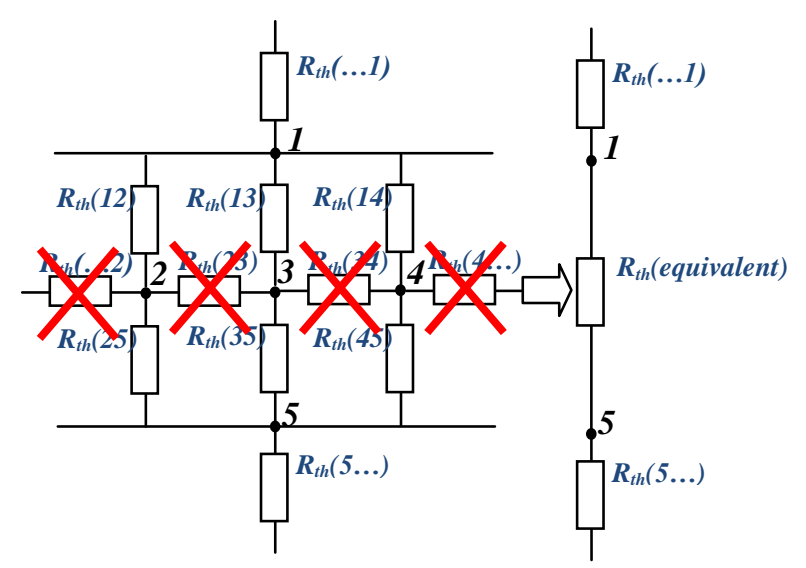

Figure 4: Equivalent resistance principle

\subsection{Third architecture}

The third method does not introduce any additional simplifications into the nodal method. In order to compare the two methods presented earlier, the nodal network taking into account all the resistances in all the directions is realized for a specific asynchronous machine.

The equivalent circuit for this method is the same as this of the second architecture, except that this time the $\varphi$-axis thermal resistances are taken into account as in Figure 2.

Taking into account of all the stator and rotor poles increases considerably the total number of nodes of the network. So with the variation of slot number the number of nodes varies also. The change of the number of nodes leads to the change of matrixes representing algebraic equations of the differential equation as one presented below. The creation of the matrixes with high number of elements is a time consuming process and could be inadmissible if a fast thermal analysis is needed.

$$
\rho V c_{p} \cdot \frac{T_{n}^{i}-T_{n}^{i-1}}{\Delta t}+\sum \frac{T_{n}^{i}-T_{m}^{i}}{R t h_{m, n}}=\phi_{n}
$$

with $\rho$ - mass density of the considered volume $\left[\mathrm{kg} \cdot \mathrm{m}^{-3}\right], V$ volume represented by its node $n\left[\mathrm{~m}^{3}\right], c_{p}$ - heat capacity of the node $n\left[\mathrm{~J} \cdot \mathrm{kg}^{-1} \cdot \mathrm{K}^{-1}\right], T$ - absolute temperature $[\mathrm{K}], \Delta t$ the time step [s], $R_{t h m, n}$ - thermal resistance between the node $n$ and a surrounding node $m\left[\mathrm{~K} . \mathrm{W}^{-1}\right]$ and $\phi_{n}$ - internal heat generation in the volume $n[\mathrm{~W}] . m$ and $n$ are spatial parameters and $i$ is a time parameter.

\subsection{Experimental validation}

Due to confidentiality reasons the results of comparison of the calculation values and experimental results couldn't be presented in this paper. However, the three architectures are compared to the results issued from the literature. The work of Pil-Wan Hab et al. [3] from the Korean Institute of Electrical Engineers has been chosen as the reference. The authors consider a 29kW, 12000rpm high speed asynchronous motor including water cooling jacket.

The design characteristics and loss values in steady state given in the article [3] are presented in the Table 1 and in the Table 2 respectively.

\begin{tabular}{|l|l|l|}
\hline Items & Values & Units \\
\hline Outer stator diameter & 135 & $\mathrm{~mm}$ \\
\hline Inner stator diameter & 88 & $\mathrm{~mm}$ \\
\hline Stack length & 150 & $\mathrm{~mm}$ \\
\hline Stator slot number & 36 & \\
\hline Rotor slot number & 34 & \\
\hline Current density of stator & 18 & $\mathrm{~A} / \mathrm{mm}^{2}$ \\
\hline Current density of rotor & 20.7 & $\mathrm{~A} / \mathrm{mm}^{2}$ \\
\hline Flux density of airgap & 0.76 & $\mathrm{~T}$ \\
\hline Electrical steel thickness & 0.35 & $\mathrm{~mm}$ \\
\hline Core loss at 1.5T/834Hz & 139 & $\mathrm{~W} / \mathrm{kg}$ \\
\hline Rotor cage conductor & copper \\
\hline
\end{tabular}

Table 1: Design parameters of the machine

\begin{tabular}{|l|l|l|}
\hline Items & Values & Units \\
\hline Stator copper loss & 622 & W \\
\hline Rotor copper loss & 453 & W \\
\hline Iron loss & 420 & W \\
\hline Mechanical loss & 197 & W \\
\hline Stray load & 863 & W \\
\hline
\end{tabular}

Table 2: Loss values in steady state

\section{Results and discussion}

\subsection{Measured results from the literature}

The results of experimental tests provided by the authors in [3] are presented in Figure 5.

The temperatures of rear and front side end windings and of slot winding after $100 \mathrm{~min}$ of functioning of the machine are following: $80.4^{\circ} \mathrm{C}, 75.2^{\circ} \mathrm{C}$ and $65.5^{\circ} \mathrm{C}$ respectively.

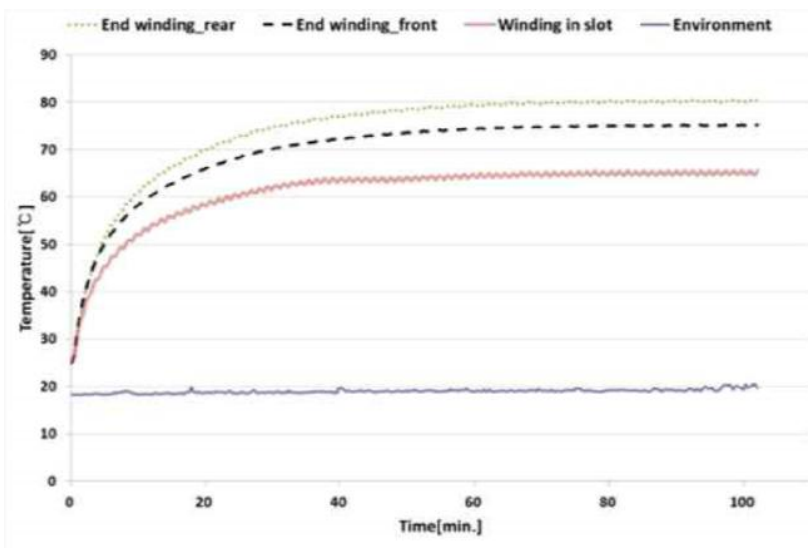

Figure 5: Mesured temperature disribution 


\subsection{Results of the three architectures}

Some values of losses, material properties and heat transfer coefficients presented in the article [4] were taken into account for the finite difference calculation.

The geometry details of the tested machine, such as insulation characteristics, winding parameters, slot type, cooling channel geometry etc., were not specified in the article [3]. So the geometry details for this machine were figured out basing on the design methodology from [4]. As the machine from [3] represents a totally enclosed machine all the missed loss values and heat transfer coefficients inside the machine were estimated basing on [5], [6], and [7].

\section{Results for the first architecture:}

The results of the thermal analysis using first method in transient mode are presented in Figure 6.

All the contact surfaces of the rotor are multiplied by the coefficient equal to the ratio of rotor and stator slot numbers.

All the losses for this method as well as all the dimensions and contact surfaces are multiplied by the adjustment coefficient.

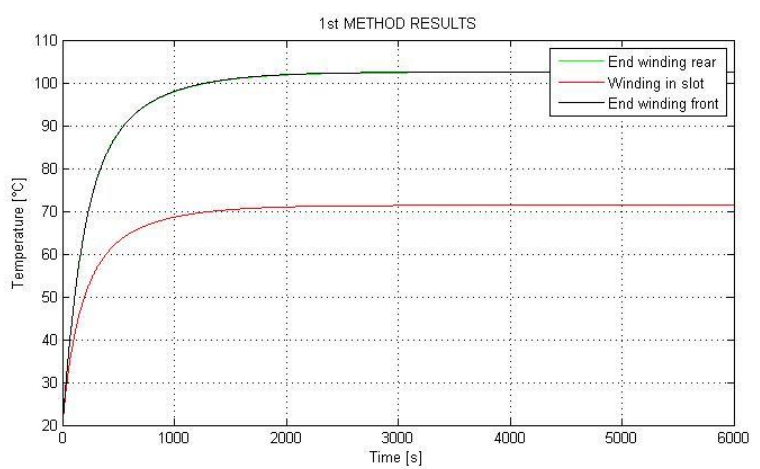

Figure 6 : Stator winding temperature distribution for the $1^{\text {st }}$ nodal network architecture

As it is seen from the graph the temperature of the rear side stator enwinding is about $103{ }^{\circ} \mathrm{C}$, of the front side $-102^{\circ} \mathrm{C}$ and winding temperature inside the slots is about $71^{\circ} \mathrm{C}$.

\section{Results for the second architecture:}

Nodal network of the second method takes into account the whole machine geometry. The principle simplification of this method is neglecting heat flux in orthoradial direction between slots winding and teeth. This simplification is justified by the fact of low heat conduction characteristics of slot insulation and the adaptation of surface contact between yoke and slot.

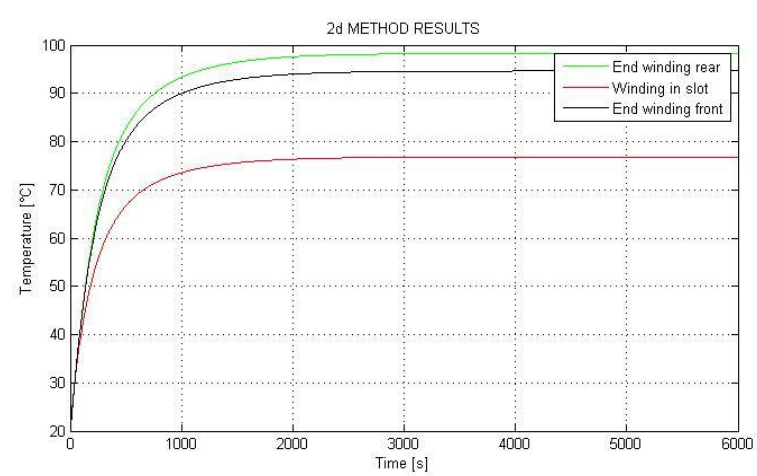

Figure 7: Stator winding temperature distribution for the $2^{\text {nd }}$ nodal network architecture

The results using the second method are presented in Figure 7. The temperature of the stator rear side enwinding is equal to $98^{\circ} \mathrm{C}$, of that one of the front side is equal $94^{\circ} \mathrm{C}$. The winding temperature inside the slots is about $74^{\circ} \mathrm{C}$.

\section{Results for the third architecture:}

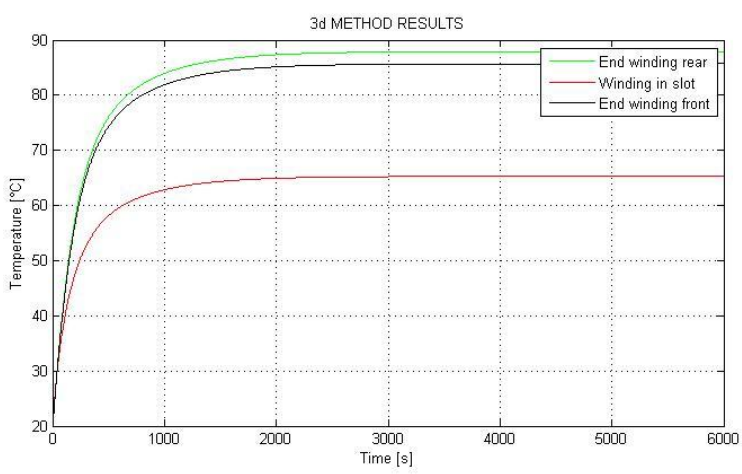

Figure 8: Stator winding temperature distribution for the $3^{\text {rd }}$ nodal network architecture

The third method takes into account the thermal paths in all the directions, including those between slots and tooth.

This method has an important time cost and the developed nodal network for this specific machine is not acceptable for other electrical machine configurations with different numbers of stator and rotor slots.

Particularly this nodal network is composed of 204 nodes. Taking into account 2378 time steps the number of calculation points increases up to 485000 .

So it is evident that such a large number of nodes is not admissible if a generalized model, permitting to provide thermal analysis of whatever machine structure, is needed.

According to results of nodal method using third nodal structure the temperature of the stator rear side enwinding is equal to $88^{\circ} \mathrm{C}$, of the front side - to $86^{\circ} \mathrm{C}$ and winding temperature inside the slots is about $65^{\circ} \mathrm{C}$. 


\section{3}

\section{Results comparison}

In the Table 2 the results of the three proposed calculation methods as well as the test results taken from the literature are presented.

As it was mentioned before, some geometry details and thermal parameters that were not presented in [3], have been estimated analytically to complete our calculation. So the difference between measured and calculated results could be easily explained by the inaccuracy of supposed values.

\begin{tabular}{|c|c|c|c|c|}
\cline { 2 - 5 } \multicolumn{1}{c|}{} & $\begin{array}{c}\text { Test } \\
\text { results }\end{array}$ & $\begin{array}{c}1^{\text {st }} \\
\text { method }\end{array}$ & $\begin{array}{c}2^{\text {nd }} \\
\text { method }\end{array}$ & $\begin{array}{c}3^{\text {rd }} \\
\text { method }\end{array}$ \\
\hline $\begin{array}{c}\text { Stator end } \\
\text { winding (rear) }\end{array}$ & $80.4^{\circ} \mathrm{C}$ & $102.6^{\circ} \mathrm{C}$ & $98.3^{\circ} \mathrm{C}$ & $87.9^{\circ} \mathrm{C}$ \\
\hline $\begin{array}{c}\text { Stator slot } \\
\text { winding }\end{array}$ & $65.5^{\circ} \mathrm{C}$ & $71.4^{\circ} \mathrm{C}$ & $73.8^{\circ} \mathrm{C}$ & $65.3^{\circ} \mathrm{C}$ \\
\hline $\begin{array}{c}\text { Stator end } \\
\text { winding (front) }\end{array}$ & $75.2^{\circ} \mathrm{C}$ & $102.4^{\circ} \mathrm{C}$ & $94.6 .^{\circ} \mathrm{C}$ & $85.7^{\circ} \mathrm{C}$ \\
\hline
\end{tabular}

Table 2: Results of thermal modelling and experimental test

The tendency of all the three methods to overestimate the temperatures is positive in point of view of the security requirements of the machine and its environment.

Nevertheless, the experimental results have to be treated carefully, knowing the high uncertainty of sensors and particularly their position sensibility in the perspective of consideration of the points with important temperature gradients.

This method permits to take into account the heat fluxes in all the directions, to keep low number of nodes, as a consequence to realize a fast thermal analysis. However, this method overestimates the temperature rise almost twice and doesn't give realistic temperatures.

It is clear that the third method taking into account all the heat flux paths and not requiring introducing of any adjustment coefficient is the most accurate. However as it was discussed earlier it is not admissible if a generalized model is needed.

The second method overestimates the temperature values for about $13 \%$. It could be useful in case if fast calculation and moderate precision are required.

\section{Conclusion}

In this article, three nodal network architectures were compared to experimental test results from the literature. The study was carried out on a $29 \mathrm{~kW}$ high speed asynchronous machine.

The difference between calculated values and experimental test results could be explained by the fact of lack of information about heat sources distribution inside the machine, geometry details such as winding length, number of turns per phase, number of parallel path etc.

As a result, it appears that the nodal architecture neglecting the heat flux in orthoradial direction between slots and teeth could be a good compromise solution for a generalized thermal model of helicopter electric propulsion system. This method permits to keep a better time cost of the model as well as a moderate precision.

\section{Acknowledgements}

This research is supported by Airbus Helicopters in partnership with the University of Bourgogne Franche-Comte (UBFC) and FEMTO-ST Institute (UMR CNRS 6174).

\section{References}

[1] John Blandino and al. "Overview of Electric Propulsion Research in U.S. Academia", AIAA-2003-4442 $39^{\text {th }}$ AIAA Joint Propulsion Conference, (July 2003).

[2] M. Necato Ozisik. "Finite Difference Method in Heat Transfer", Mechanical and Aerospace Engineering Department North Carolina State University, CRC Press, volume 432, (1994).

[3] P-W. Han, J-H. Choi, D-J. Kim, Y-D. Chun, D-J. Bang. "Thermal Analysis of High Speed Induction Motor by Using Lumped-Circuit Parameters", Journal of Electrical Engineering \& Technology, volume 10, pp. 709-714, (2015).

[4] A.K. Sawhney. "Electrical Machine Design", Dhanpat Rai \& Co. (P) Ltd., volume 1128, (2014).

[5] A. Bousbaine. "An Investigation into the Thermal Modelling of Induction Motors", Thesis submitted to the University of Sheffield for the Degree of Doctor of Philosophy, volume 162, (1993).

[6] J. Pyrhonen, T. Jokinen, V. Hrabovcova. "Design of Rotating Machines", John Wiley \& Sons, Ltd. ISBN: 978-0-470-69516-6, volume 502, (2008).

[7] M. Jaaskelainen. "Determination of coefficients of thermal convection in a high speed electrical machine", Thesis submitted to the Helsinki University of Technology for the Degree of Master of Science in Technology, volume 45, (2009). 